\title{
Morphological and Mechanical Characteristics of Onion Seedlings Insight to Mechanized Transplantation
}

\begin{abstract}
Background: Onion is a widely accepted as vegetable as well as spice crop, sharing a 14.31 lakh ha area with 267.3 lakh MT production in 2020. Improved management structure and healthy seedling are important factors in overcoming the cause and even developing effective transplanter. The information of morphological properties is essential before designing modern farming equipment. Methods: Present study focuses on the properties and age of seedlings for automated transplanting, five majorly cultivated varieties of onion Light red gavran, N-53 Nasik red, AFDR, KSP-117 and Nafed were selected. The morphological (height, weight, diameter) and mechanical (compressive strength and static coefficient of friction) properties were measured under 10 days intervals to compare 30-70 days seedling.

Result: Bulb and stem diameter were in the range from 2.82 to $3.82 \mathrm{~mm}$ and 0.86 to $2.12 \mathrm{~mm}$, respectively. The model was found significantly different with concerning days. Plywood and aluminium had less influence on the seedling's outer surface moisture content. The morphological parameters and compressive strength increased while a static coefficient of friction reduced with an increase in the age of the seedling. Regression and ANN (using FFBP method) models were developed for the prediction of compressive strength of seedling stem as well as a bulb with respect to the age and diameter. The ANN model was found best with the coefficient of determination of 0.76 . It is concluded that 60 and 70 days, seedling is best suited for mechanical or automated transplanting.
\end{abstract}

Key words: ANN models, Diameter, Morphological properties, Mechanical properties, Onion seedling, Regression.

\section{INTRODUCTION}

Onion is a bulb-oriented spice crop, except root all other parts viz. bulb, stem and leaves are edible. The onion growing area in the country was 14.31 lakh ha in 2020, with production of 267.3 lakh metric ton (MT). For transplanting operation of onion cultivation, manual transplanting is majorly adopted traditionally. This method is expensive and labour consuming due to close spacing than other vegetable crop, which can be significantly reduced by mechanization. Healthy seedling transplanted mechanically on the field also provide the best opportunity to harvest the onion in a mechanized way with providing uniform growth in whole field.

The information of morphological properties is essential before designing modern farming equipment. Properties of seedlings such as height, diameter, canopy of seedlings is required parameters for design and safety of the transplanting machine (Khadatkar et al., 2020). Careful handling of seedlings with minimum damage, depends on the components' working pattern during transplanting operation. Automation is based upon seedlings' characteristics in relation to crop ecology and physiology (Sakaue, 1996). A proper age of the seedlings is important to provides the adequate strength required for mechanical transplanting, which will reduce damage, increase the survival rate and viability. But very few literatures (Pandirwar et al., 2015; Khadatkar et al., 2020) are available in the area of morphological properties of onion seedlings in relation to transplanting mechanism.

Plug, pot and bare root seedlings are mostly preferred under different mechanical way of transplanting. Handheld,
Central Institute of Agricultural Engineering, Bhopal- 462 038, Madhya Pradesh, India.

Corresponding Author: V. Pagare, Central Institute of Agricultural Engineering, Bhopal-462 038, Madhya Pradesh, India.

Email: pagare.vikas7991@gmail.com

How to cite this article: Pagare, V., Din, M., Mehta, C.R., Nandede, B.M. and Kumar, M. (2022). Morphological and Mechanical Characteristics of Onion Seedlings Insight to Mechanized Transplantation. Indian Journal of Agricultural Research. DOI: $10.18805 /$ IJARe.A-5844.

Submitted: 05-06-2021 Accepted: 04-01-2022 Online: 19-02-2022

semi-automatic, automatic and robotic transplanting mechanisms have been developed by using the versatile properties of seedlings. Handheld vegetable transplanter developed by Nandede et al. (2017) are considered mainly compressive strength property to resist the damage during gravity drop from certain height and correctly transplanted. Semi-automatic transplanter was developed by many researchers with using various mechanism for, plug and pot type seedlings [Chaudhari et al., 2002 (finger type); Pandirwar et al., 2019 (plug and finger type) and; Nandede, 2013 (multi stalk of metering wheel with slotted plate)]. Bare root seedlings are transplanted by plug and finger type mechanism, it works based on compressive strength of seedling stem. Height and stem diameter also influences the design of mechanism. In a gravity drop system, weight of bare root seedling influences majorly the transplanting performance. Therefore, effective age of seedling needed to acquire higher weight. 
Some researchers have developed the automatic transplanting mechanism, using the different properties of seedling, [Vivek et al., 2017 (automatic pneumatic gripping type mechanism); Kumawat et al., 2020 (conveying belt with cutting unit for hexagonal shape paper pot chain); Khadatkar et al., 2020 (embedded system)]. Pneumatic gripping type system needed adequate strength of seedling to protect from damage during gripping and releasing. For robotic transplanting, robotic arm and its gripping system were developed based on corresponding height and other factors. A Robotic transplanting mechanism was also developed by K. Rahul (2020) 4 DOF parallel robotic arm. The picking and placing are carried out with using a gripper arm. This also requires the base properties of seedling as input. Hence, the basic information about the seedling is needed to design and development of transplanter.

This study focused to evaluate the morphological and mechanical properties of different varieties of onion seedlings, which could be useful to provide the paramount information for design and development of onion seedlings transplantation in a mechanical way.

\section{MATERIALS AND METHODS}

Research was conducted on June 2020 with five different varieties of onion at Central Institute of Agricultural Engineering, Bhopal. The onion varieties namely, Light red gavran, N-53 Nasik red, AFDR, KSP-117 and Nafed were selected. These varieties are widely cultivated in the central region of India. Seeds of onion were planted in well pulverized clay soil (Vertisols). Standard agronomical procedures were followed to prepare the nursery. Seedlings were matured after 35-40 days (Anonymous 2021) to transplant into the field but higher strengthened seedling is needed in the aspect of mechanical transplanting for which this span is increased. Morphological parameters were observed during the period from the age of 30 days to 70 days. Onion seedling's sample were randomly collected from the field and fifty samples were collected from each plot to take the different parameters.

\section{Moisture content}

It is necessary to have proper knowledge about exact moisture content of seedlings to know the interaction effect with mechanical equipment's. ASAE Standard (1997) S358.2 (DEC93) was used for finding the moisture content (wet basis). The seedling samples were cut into thin pieces and kept into the oven at $103^{\circ} \mathrm{C}$ for the period of 24 hours. Moisture content of seedling was determined by observing the weight for fresh and oven dry seedlings by the weighing balance having least count $0.0001 \mathrm{~g}$ (Make by Citizen CY 304).

\section{Weight of seedling (with and without de-topping)}

Slightly heavier seedling with adequate strength is a necessity for mechanical/automatic transplanting, especially for bare root seedlings. Hence, the weight of onion seedlings with and without de-topping was measured. Ten observations were taken with three replications by using weighing balance 'Citizen CY 304' having least count $0.0001 \mathrm{~g}$.

\section{Linear dimension of seedlings}

The maximum length of outer edge of onion bulb were measured bulb diameter while the stem diameter measured at the collar (upper portion of onion bulb) by using vernier calliper having least count $0.01 \mathrm{~mm}$ (make: Baker; model: SDN 30). For this study, twenty-five observations were taken and data was analysed.

Height of seedling is important factor from designing point of view and to determine the length of plugs and fingers, dropping funnel length and alignment, press wheel diameter. However, de-topping is needed before mechanical transplant (Pandirwar et al., 2015) due to the unwanted interference by longer seedlings $(30-40 \mathrm{~cm})$ with maintaining the intra row spacing i.e., recommended about $10 \mathrm{~cm}$. Five times observations were taken for each variety and measured by the meter tape.

\section{Coefficient of static friction}

Appropriate material enhances the effectiveness of transplanting machines' performance and assisted to the reduction of total casting of machine. Hence, coefficient of friction was measured for five materials viz Plywood (W), Plastic (P), Mild steel (MS), Aluminium (Al) and Stainless steel (SS) for full and de-topped seedlings. The seedlings were put along the slope into the horizontal platforms. It was gently inclined the platform up until the seedling slipped (Impending slip) at a certain angle. It was recorded and computed by following equation:

Where,

$$
\mu=\tan \delta
$$

$\mu=$ Coefficient of friction.

$\delta=$ Impending slip angle, degree.

\section{Compressive strength}

The ability of a seedling to resist mechanical interference indicates its strength. The compressive strength of onion bulb and stem were measured through the texture analyser (TA.XT.Plus; make:Stable Micro System,UK) having load capacity $50 \mathrm{~kg}$, by using the half inch cylindrical ebonite probe having $25 \mathrm{~mm}$ diameter were used. It was compressed about $30 \%$ of bulb and stem diameter, with $0.5 \mathrm{~mm} / \mathrm{s}$ test speed to find the strength as well as to minimize the seedling damage and mortality (Pandirwar et al. 2015).

\section{Comparison to the approach for prediction of compressive strength}

Robotic transplanting or automation mainly works based on its model, which works behind the layer, by using many components i.e., languages, micro-controller, manipulator, actuator etc. Many types of mathematical and statistical models were used to solve complex problem for doing any specific task by using basic physical properties of the agricultural products. The prediction of compressive force of seedling is needed for actuating the gripping arm within 
safest limit of seedling. Under this study, two methods were used to develop the model for predicting compressive strength and comparison. Specified 125 observations were selected for onion bulb and 50 observations were taken for stem of seedlings. Empirical model (multiple linear regression) was developed for predicting the compressive strength of onion seedling stems and bulbs. On other hand, neural network approach was used to predict the compressive force. Both methods were compared on the basis of its findings.

\section{Regression approach}

Multiple linear regression was used to develop model to predict compressive strength of onion seedling stem and bulb. Model was generated by using Weka 3.9.5. The independent parameters were considered as day and diameter of bulb/stem. Correlation and multiple linear regression were observed at $5 \%$ level of significance. The equation is stated as

Where,

$$
Y=a X_{1}+b X_{2}+C
$$

$\mathrm{Y}=$ Compressive strength, $\mathrm{N}$.

$X_{1}=$ Number of days.

$\mathrm{X}_{2}=$ Diameter of seedling bulb/stem, $\mathrm{mm}$.

$a, b, C=$ constant.

\section{Neural network approach}

An artificial neural network functions by combining a number of nodes called artificial neurons. In neurons, a signal is sent only if it crosses a certain threshold. A pair of interconnected artificial neurons could transmit and coordinate information under different layers via signal. ANN directly learns and makes a relationship between input $(X)$ and output $(\mathrm{Y})$. Between the input and output layers, a number of hidden layers are available, so that a feed-forward backpropagation network is generated in this manner (Nagar, 2020). The basic structure was shown in Fig 1.

Neural network was applied for the prediction model with collected data of onion bulb and stem and was evaluated using MATLAB R2016a. An equal number of observations were taken, as in regression approach. Some parameters were fed for creating the feed forward back propagation network, such as number of input layer $=1$; output layer $=1$; hidden layer = 1; number of neurons $=2$; Levenberg-Marquardt transfer function (trainlm) are used for training (Dahikar et al., 2015). Training, validation and testing were done during prediction model process and evaluate both models.

\section{Statistical analysis of morphological properties of onion} seedling

Morphological parameters of onion seedlings were collected for different days at specific intervals and analysed in SAS 9.3 for finding the ANOVA under factorial experiment in CRD (Completely randomised design). The analysis was done and observed at $1 \%$ level of significance.

\section{RESULTS AND DISCUSSION}

The experiments were conducted to evaluate the morphology of onion seedlings i.e., linear and frictional properties as discussed. The appropriate age of seedlings can be decided in the aspect of mechanical transplanting. Data were collected by using seedlings', age from 30 to 70 days after sowing.

\section{Seedling moisture content}

The average moisture content (wet basis) of onion seedlings for all five varieties was found in the range which varied from $88.91 \%$ to $92.83 \%$ under all day's observations. Its standard deviation varied from 0.62 to $4.56 \%$. Moisture content was recorded between 91.84 to $90.68 \%$ (Light red gavran); 92.83 to $90.65 \%$ (N-53 Nasik red), 92.64 to $91.62 \%$ (AFDR), 91.33 to $91.76 \%$ (KSP-117) and 91.57 to $89.27 \%$ (Nafed), respectively for 30 to 70 days. The moisture content of seedling was slightly reduced with age in all the varieties and this result was in agreement with Pandirwar et al., (2015).

\section{Weight of seedlings}

The weight of bare root onion seedling was measured as depicted in Table 1. It was further measured de-topped and dry weight of seedling. The growth rate was found higher in Light red gavran variety while the lowest growth was found in KSP-117. The higher weight of seedling was found for

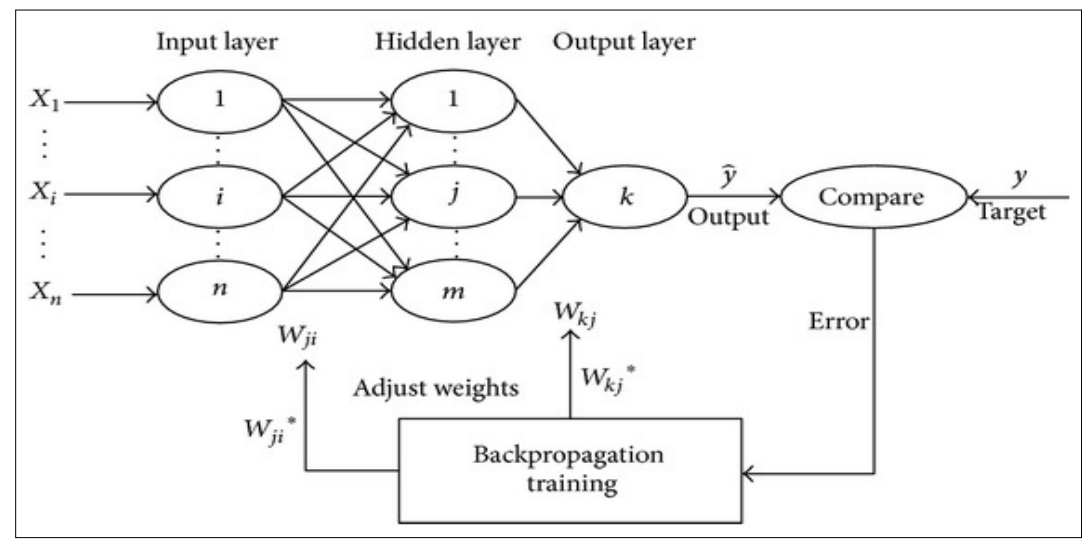

Fig 1: Feed forward and back propagation neural network structure. 
Morphological and Mechanical Characteristics of Onion Seedlings Insight to Mechanized Transplantation

Table 1: Weight of onion seedling of different varieties at different growing stage.

\begin{tabular}{|c|c|c|c|c|c|}
\hline Days & 30 & 40 & 50 & 60 & 70 \\
\hline & \multicolumn{5}{|c|}{ Light Red Gavraan } \\
\hline $\mathrm{W}_{\mathrm{sw}}, \mathrm{mg}$ & $234 \pm 49.2$ & $324 \pm 74.2$ & $623.02 \pm 251.6$ & $901.38 \pm 116.3$ & $964.54 \pm 206.6$ \\
\hline $\mathrm{W}_{\mathrm{dtpw}}, \mathrm{mg}$ & $170 \pm 31.0$ & $222 \pm 11.7$ & $556.38 \pm 159.4$ & $436.1 \pm 177.9$ & $650.34 \pm 83.5$ \\
\hline \multirow{2}{*}{$\mathrm{W}_{\mathrm{sdrw}}, \mathrm{mg}$} & $17.84 \pm 4.0$ & $33.03 \pm 9.9$ & $59.74 \pm 24.8$ & $66.944 \pm 21.4$ & $80.34 \pm 14.3$ \\
\hline & \multicolumn{5}{|c|}{ N-53 Nasik Red } \\
\hline$W_{s w}, m g$ & $212 \pm 70.5$ & $284 \pm 53.9$ & $444.54 \pm 106.2$ & $703.64 \pm 114.5$ & $751.84 \pm 153.8$ \\
\hline $\mathrm{W}_{\mathrm{dtpw}}, \mathrm{mg}$ & $146 \pm 41.8$ & $230 \pm 49.8$ & $268.28 \pm 52.8$ & $494.94 \pm 87.1$ & $505.2 \pm 76.9$ \\
\hline \multirow{2}{*}{$\mathrm{W}_{\mathrm{sdrw}}, \mathrm{mg}$} & $16.72 \pm 5.6$ & $27.17 \pm 7.2$ & $42.84 \pm 7.8$ & $53.16 \pm 10.3$ & $57.56 \pm 10.8$ \\
\hline & \multicolumn{5}{|c|}{ AFDR } \\
\hline $\mathrm{W}_{\mathrm{sw}}, \mathrm{mg}$ & $263.72 \pm 65.3$ & $325.54 \pm 97$ & $405.6 \pm 164.9$ & $378.44 \pm 99.9$ & $786.92 \pm 168.5$ \\
\hline $\mathrm{W}_{\mathrm{dtpw}}, \mathrm{mg}$ & $201.06 \pm 47.6$ & $369.26 \pm 121.2$ & $280.64 \pm 67.6$ & $532.5 \pm 85$ & $459.32 \pm 27.2$ \\
\hline \multirow[t]{2}{*}{$\mathrm{W}_{\text {sdrw }}, \mathrm{mg}$} & $19.88 \pm 3.6$ & $31.54 \pm 10.1$ & $49.58 \pm 12.5$ & $42.04 \pm 8.6$ & $77.38 \pm 3.5$ \\
\hline & \multicolumn{5}{|c|}{ KSP-117 } \\
\hline $\mathrm{W}_{\mathrm{sw}}, \mathrm{mg}$ & $254.26 \pm 78.4$ & $287.12 \pm 146.9$ & $223.56 \pm 113.3$ & $491.26 \pm 124.9$ & $412.7 \pm 134.8$ \\
\hline $\mathrm{W}_{\mathrm{dtpw}}, \mathrm{mg}$ & $212.14 \pm 53.1$ & $246.86 \pm 74.9$ & $264.92 \pm 90$ & $370.3 \pm 99.3$ & $420.04 \pm 95.9$ \\
\hline \multirow{2}{*}{$\mathrm{W}_{\text {sdrw }}, \mathrm{mg}$} & $23.02 \pm 7.6$ & $24.84 \pm 13.3$ & $24.12 \pm 12.2$ & $51.14 \pm 16.8$ & $50.08 \pm 12.7$ \\
\hline & \multicolumn{5}{|c|}{ Nafed } \\
\hline $\mathrm{W}_{\mathrm{sw}}, \mathrm{mg}$ & $405.9 \pm 172.9$ & $448.2 \pm 30.5$ & $640.12 \pm 236.3$ & $679.54 \pm 138.5$ & $519.24 \pm 219.7$ \\
\hline $\mathrm{W}_{\mathrm{dtpw}}, \mathrm{mg}$ & $256.16 \pm 111.5$ & $311.42 \pm 7.2$ & $438.5 \pm 181.2$ & $489.22 \pm 56.5$ & $519.64 \pm 180.2$ \\
\hline $\mathrm{W}_{\mathrm{sdrw}}, \mathrm{mg}$ & $31.66 \pm 2.1$ & $39.34 \pm 17.0$ & $47.36 \pm 15.6$ & $58.92 \pm 11.6$ & $58.54 \pm 10.6$ \\
\hline
\end{tabular}

$\mathrm{W}_{\mathrm{sw}}$ - Seedling weigh; $\mathrm{W}_{\mathrm{dtpw}}-$ De-topped seedling weight; $\mathrm{W}_{\text {sdrw }}$ - Seedling dry weight.

Light red gavran and it was $964.54 \mathrm{mg}, 65.34 \mathrm{mg}$ and 80.34 $\mathrm{mg}$ for full, de-topped and dry weight seedling, respectively, among all varieties.

Similarly, the lowest weight was found as $412.7,420.04$ and $50.8 \mathrm{mg}$ for full, de-topped and dry seedlings in KSP117. The statistical model was found difference significantly (at $1 \%$ level of significance) in aspect of days for seedling weight, de-topped weight and dry weight as well. Similarly, the significant difference found among all varieties for seedling dry weight. The major reason in the variation of the weight was the quality of different varieties. It may be due to change in environmental conditions during seedlings' growth.

\section{Number of leaves}

There was no significant difference observed in number of leaves among all varieties; However, it was significantly different with respect to days. The number of leaves per plant were observed to be in the range from 2 to 4 during nursery stage. The maximum growth rate of leaves was observed for Light red gavran and N-53 Nasik red variety. It was found to be $3.4 \pm 0.49$ and $3.2 \pm 0.40$ for Light red gavran and N-53 Nasik red variety, respectively.

\section{Bulb and stem diameter of seedling}

The onion bulb and stem diameter are depicted in Table 2, which reflect the growing status of factors in the nursery stage. The onion bulb diameter was found in the range from 1.28 to $3.82 \mathrm{~mm}$ from 30 to 70 days after planting. Maximum bulb diameter was observed as $3.82 \pm 0.66 \mathrm{~mm}$ under AFDR variety, while lowest diameter was found as $2.82 \pm 0.58 \mathrm{~mm}$ for N-53 Nasik red during the same period. On other hand, the maximum stem diameter was observed as $2.12 \pm 0.58$ $\mathrm{mm}$ for Nafed, followed by AFDR, N-53 Nasik red, Light red gavran and KSP-117.

\section{Height of seedling}

The seedling height is presented for all five varieties in Table 2, from 30 to 70 days growth period, was observed from 115 to $263 \mathrm{~mm}$ and reflected gradual increment during nursery growing. However, after 60 days of planting, these increments reduced slightly due to adverse climate conditions. Among all five varieties the maximum height (263 $\mathrm{mm}$ ) was found in Nafed, followed by N-53 Nasik red (234 $\mathrm{mm}$ ), Light red gavran (232 mm), AFDR (192 mm) and KSP$117(158 \mathrm{~mm})$, respectively. The height of seedlings was reduced by de-topping process prior to transplanting operation thereby seedling uniformity acquired for effective mechanical handling.

The comparative evaluation shows that onion seedling weight increased gradually with increasing the physical parameters (height and diameter of seedling) (Fig 2a). Seedling weight increased from 282.43 to $631.67 \mathrm{mg}$ with increasing the bulb diameter from 1.96 to $3.24 \mathrm{~mm}$ during 30 to 70 days observation ( $F$ ig $2 b$ ). The value was slightly lower than that observed by Pandirwar et al., (2015) and Khadatkar et al., (2020) and the reason behind this may be the nursery grown under shadenet. Linear relation was observed between stem and bulb diameter of seedling. The coefficient of determination was found as 0.96 (Fig 2c), which depicts the higher relation between them. The analysis would be assisted to future automation in transplanting system. 
Morphological and Mechanical Characteristics of Onion Seedlings Insight to Mechanized Transplantation

Table 2: No. of leaves, height, bulb and stem diameter of onion seedlings.

\begin{tabular}{|c|c|c|c|c|c|}
\hline Days & 30 & 40 & 50 & 60 & 70 \\
\hline & \multicolumn{5}{|c|}{ Light Red Gavraan } \\
\hline No. & $2.2 \pm 0.4$ & $2.2 \pm 0.40$ & 3 & $3 \pm 0.63$ & $3.4 \pm 0.49$ \\
\hline $\mathrm{H}, \mathrm{mm}$ & $160 \pm 28.3$ & $161 \pm 23.1$ & $193 \pm 30.3$ & $230 \pm 20.0$ & $232 \pm 29.1$ \\
\hline $\mathrm{D}_{\mathrm{B}}, \mathrm{mm}$ & $1.82 \pm 0.33$ & $1.72 \pm 0.15$ & $2.92 \pm 0.87$ & $3.28 \pm 0.31$ & $3.65 \pm 0.66$ \\
\hline \multirow[t]{2}{*}{$\mathrm{D}_{\mathrm{s}}, \mathrm{mm}$} & $1.16 \pm 0.20$ & $1.08 \pm 0.20$ & $1.86 \pm 0.30$ & $1.72 \pm 0.20$ & $1.88 \pm 0.50$ \\
\hline & \multicolumn{5}{|c|}{ N-53 Nasik Red } \\
\hline No. & 2 & $2.2 \pm 0.40$ & 3 & $2.6 \pm 0.49$ & $3 \pm 0.63$ \\
\hline $\mathrm{H}, \mathrm{mm}$ & $125 \pm 28.6$ & $179 \pm 21.1$ & $198 \pm 21.4$ & $214 \pm 32.6$ & $234 \pm 56.8$ \\
\hline$D_{B}, m m$ & $1.28 \pm 0.21$ & $1.66 \pm 0.14$ & $2.93 \pm 0.50$ & $2.18 \pm 0.36$ & $2.82 \pm 0.58$ \\
\hline \multirow[t]{2}{*}{$\mathrm{D}_{\mathrm{s}}, \mathrm{mm}$} & $0.86 \pm 0.10$ & $1.12 \pm 0.10$ & $1.72 \pm 0.20$ & $1.58 \pm 0.30$ & $1.92 \pm 0.30$ \\
\hline & \multicolumn{5}{|c|}{ AFDR } \\
\hline No. & 3 & $2.6 \pm 0.49$ & $2.2 \pm 0.75$ & $2.8 \pm 0.40$ & $2.4 \pm 0.49$ \\
\hline $\mathrm{H}, \mathrm{mm}$ & $115.4 \pm 10.6$ & $187 \pm 30.9$ & $177.2 \pm 25.4$ & $180 \pm 31.6$ & $192 \pm 18.6$ \\
\hline$D_{B}, m m$ & $1.86 \pm 0.47$ & $2.7 \pm 0.28$ & $2.76 \pm 0.54$ & $3.38 \pm 0.99$ & $3.82 \pm 0.66$ \\
\hline \multirow[t]{2}{*}{$\mathrm{D}_{\mathrm{s}}, \mathrm{mm}$} & $0.86 \pm 0.20$ & $1.38 \pm 0.10$ & $1.63 \pm 0.30$ & $2.08 \pm 0.30$ & $2.02 \pm 0.60$ \\
\hline & \multicolumn{5}{|c|}{ KSP-117 } \\
\hline No. & $2.2 \pm 0.40$ & $2.6 \pm 0.50$ & $1.6 \pm 0.50$ & $2.4 \pm 0.50$ & 3 \\
\hline $\mathrm{H}, \mathrm{mm}$ & $130 \pm 7.1$ & $168 \pm 18.6$ & $120 \pm 30.3$ & $209 \pm 19.6$ & $158 \pm 14.4$ \\
\hline$D_{B}, m m$ & $2.62 \pm 0.77$ & $2.69 \pm 0.57$ & $3.14 \pm 1.23$ & $3.2 \pm 0.52$ & $3.48 \pm 0.96$ \\
\hline \multirow[t]{2}{*}{$D_{s}, m m$} & $0.88 \pm 0.10$ & $1.32 \pm 0.40$ & $1.48 \pm 0.20$ & $1.78 \pm 0.20$ & $1.82 \pm 0.40$ \\
\hline & \multicolumn{5}{|c|}{ Nafed } \\
\hline No. & $2.2 \pm 0.40$ & $2.6 \pm 0.49$ & $2.4 \pm 0.49$ & $3 \pm 0.63$ & $3.2 \pm 0.40$ \\
\hline $\mathrm{H}, \mathrm{mm}$ & $12 \pm 17.2$ & $163 \pm 34.3$ & $201 \pm 19.6$ & $207 \pm 30.6$ & $263 \pm 29.7$ \\
\hline $\mathrm{D}_{\mathrm{B}}, \mathrm{mm}$ & $2.22 \pm 0.19$ & $2.56 \pm 0.39$ & $2.58 \pm 0.74$ & $3.3 \pm 0.72$ & $3.52 \pm 0.35$ \\
\hline $\mathrm{D}_{\mathrm{S}}, \mathrm{mm}$ & $0.96 \pm 0.19$ & $1.59 \pm 0.46$ & $1.61 \pm 0.42$ & $2.1 \pm 0.33$ & $2.12 \pm 0.58$ \\
\hline
\end{tabular}

No- Number of leaves; $\mathrm{H}$ - Height of seedlings; $D_{B}$ - Bulb diameter: $D_{S}-$ Stem diameter of seedlings.

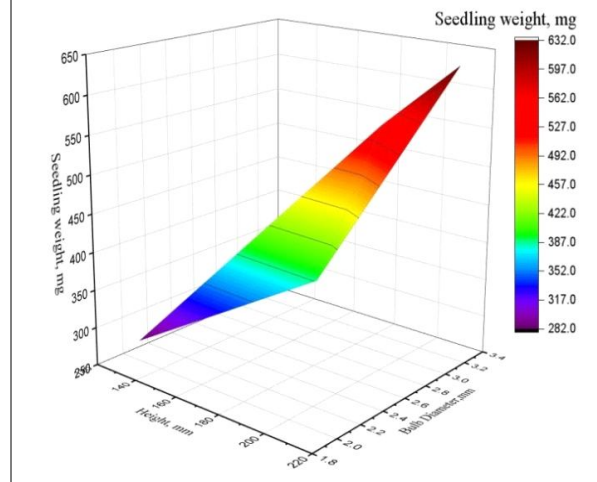

a.

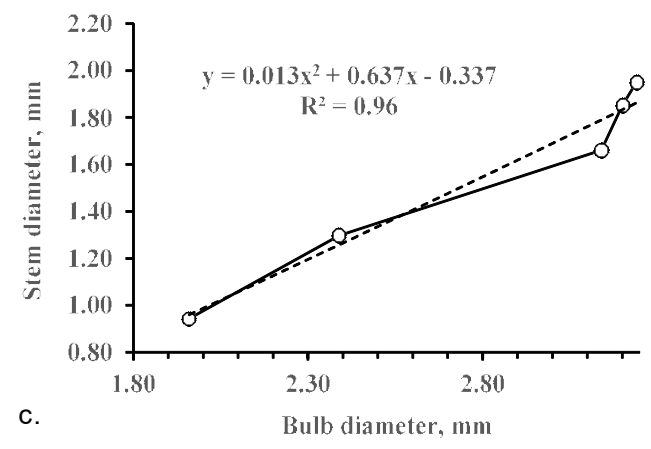

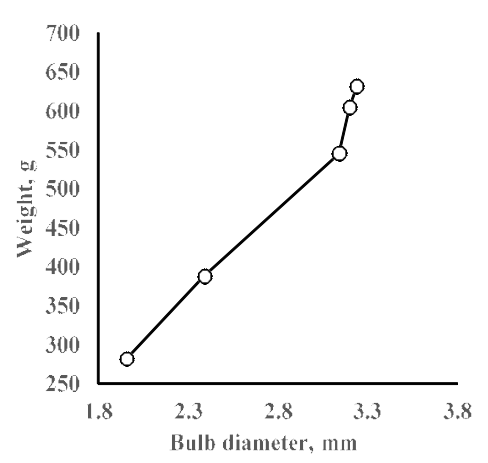

b. (1)

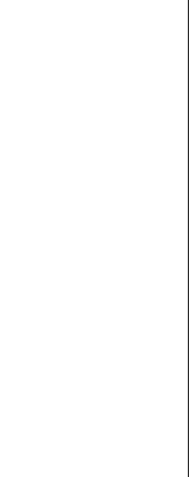

Fig 2: Relation of different parameters of onion seedlings; a. Seedling weight, bulb diameter and height; b. weight and bulb diameter; c. stem diameter and bulb diameter. 
Morphological and Mechanical Characteristics of Onion Seedlings Insight to Mechanized Transplantation

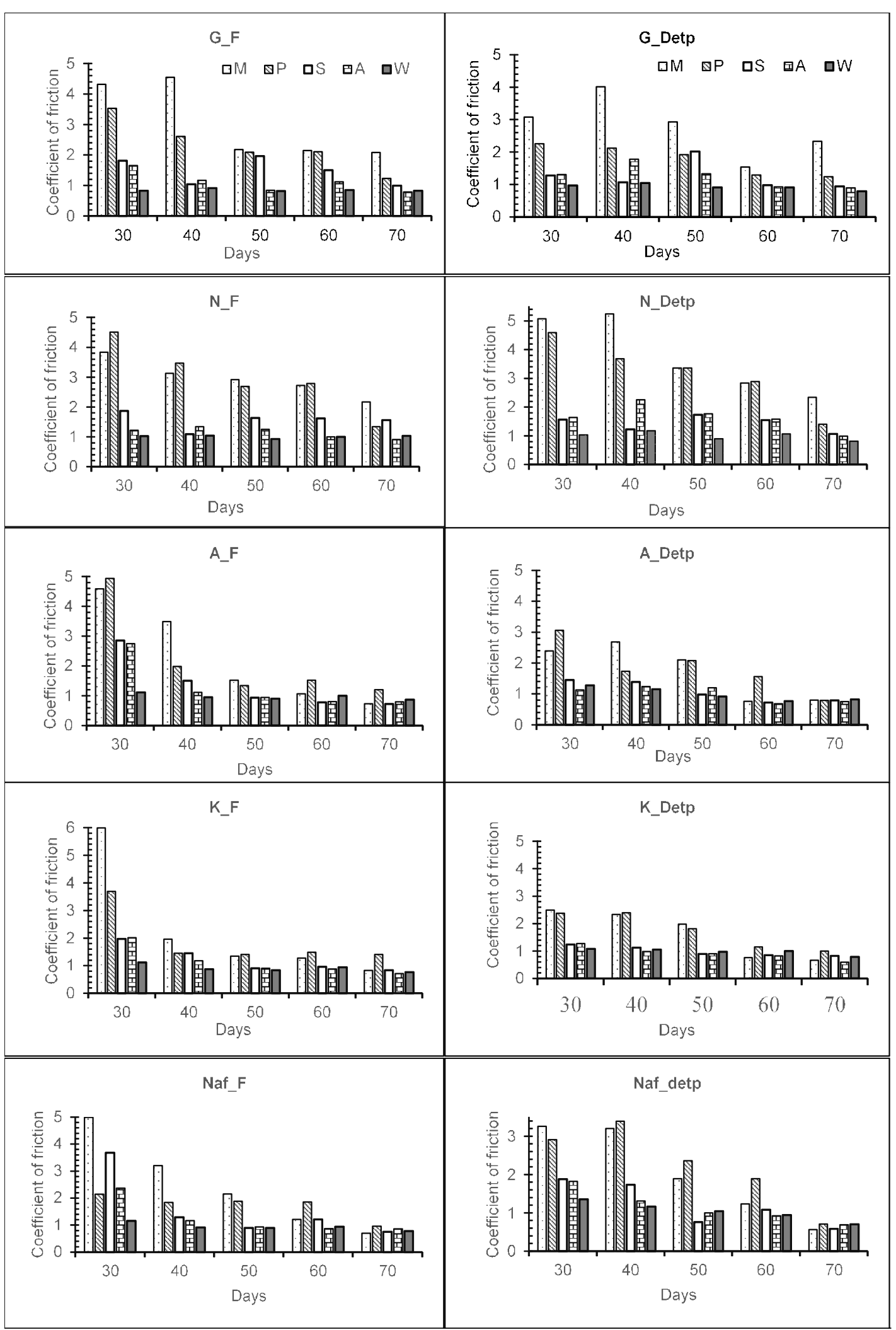

Fig 3: Coeffiecient of friction under different varities for full (F) and detopped (detp) seedling, G- Gavran; N- Nasik Red; A- AFDR; KKSP-117 and Naf- Nafed. 


\section{Coefficient of static friction (CF)}

The average coefficient of friction (Fig 3) was found in the range between 0.70 to $1.35,0.71-4.94,0.66-5.24,0.69-2.26$ and 0.58-3.68 for Plywood (W), Plastic (P), Mild steel (MS), Aluminium (Al) and Stainless steel (SS), respectively. Plastic shows the higher CF among all platforms, but the nature of gradual reduction of CF with age of seedling are similar as findings by other researchers. The significant differences were found in CF with respect to the varieties, age of seedlings as well as with used platforms (at $1 \%$ level of significance). The CF had reciprocal relation with age of seedlings.

Thirty days old onion seedling (not matured properly) had higher coefficient of friction due to more soft, flexible and lighter in weight. Another reason of higher CF are the shorter leaves of seedlings, which adhere easily to the material surface and do not allow seedling to displace from specified position. Seedling weight increased with age. Thereby higher weight, easily assisted to displace the seedling during operation and did not affect much by the outer surface moisture content of seedling. Thus, they roll down at a lower static friction (Khura et al., 2010; Pandirwar et al., 2015). Based on findings plastic material had higher CF as compared to other materials (Fig 3). Plywood and Aluminium material had affected less by the moisture content of seedling. Its variation was found less with increment in age. On other hand, higher age seedling (60 to 70 day) had lesser coefficient of friction, as compared to lower age seedling.

\section{Compressive strength}

The compressive strength of bulb/stem of seedling is presented in Fig 4. The mean value of bulb and stem of onion seedling ranged from 5.44 to $12.74 \mathrm{~N}$ and 2.46 to $7.23 \mathrm{~N}$, respectively. The maximum value of CS of bulb was 13.21 $\mathrm{N}$ at 70 days for Nafed variety while minimum was observed as $4.77 \mathrm{~N}$ at 30 days for AFDR variety Seedling's bulb exhibits significant differences for varieties and days, whereas the stem only showed a significant difference for days. The maximum CS was $8.13 \mathrm{~N}$ at 70 days of stem for KSP-117 and minimum CS was $1.87 \mathrm{~N}$ at 30 days for Light red gavran variety.

As bulb and stem diameters increased, CS gradually increased. Findings are supported with the conclusion by Khura et al. (2010). A 60 to 70-day-old onion seedling was found to be more appropriate and easier to transplant using an automatic or mechanical transplanter that is more robust. Observed data of physical parameters of seedlings may helpful for designing of transplanter to smooth operation of transplanter and for automation. Seedling bulb diameter and stem diameter had a strong relation to transplanter. The coefficient of determination was found to be 0.98 and 0.97 for bulb and stem of onion seedling, respectively.

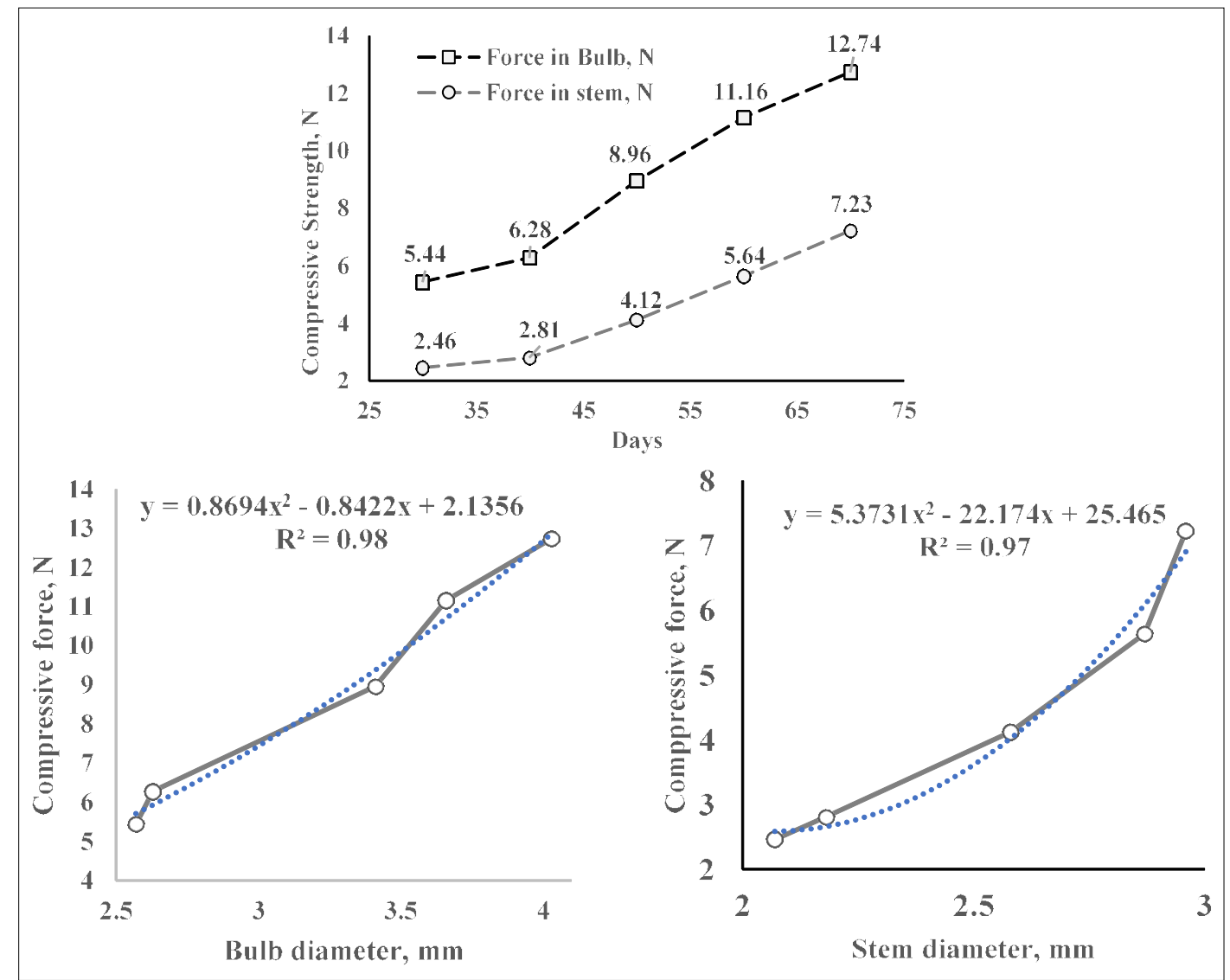

Fig 4: Compressive strength of bulb and stem of onion seedling with respect to days, bulb diameter and stem diameter. 


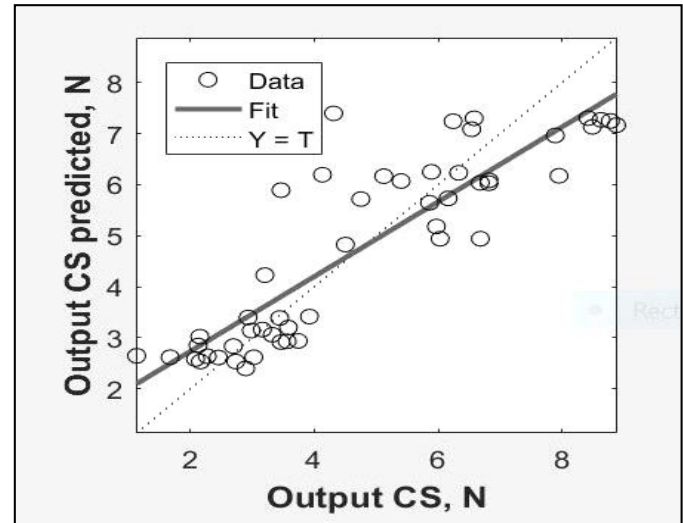

a.

Fig 5: Compressive strength of stem (a) and bulb (b) with its predicted value.

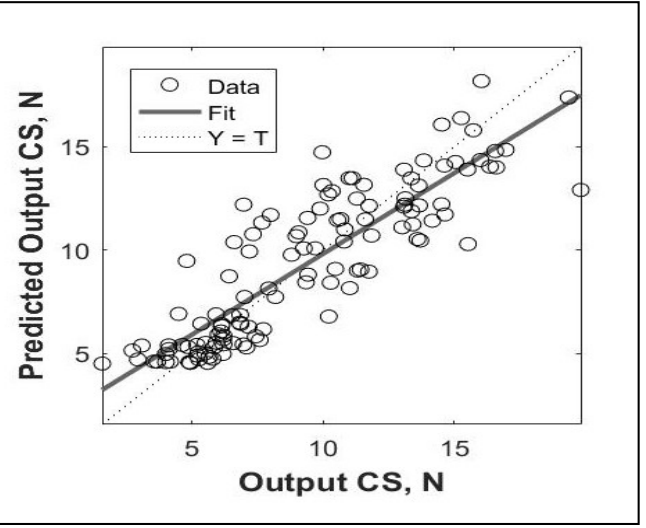

b.

\section{Regression analysis}

The multiple regression analysis was done to predict the compressive strength of onion seedlings' stem and bulb. The imperial equation (Table 3) was developed to predict the strength by taking two independent variables as number of days and diameter of seedlings. The multiple regression with proposed equation was found to be fit with the value 0.75 for coefficient of determination $\left(R^{2}\right)$ of onion bulb and stem, while its root mean square error (RMSE) was found to be 2.02 and 1.07 , in same manner respectively. The overall regression model was highly significant at, $F(2,122)$ $=200.84, p<0.001$ and both parameters are significant with the compressive strength.

\section{Neural network approach}

On the basis of physical observations of the parameters, data were trained for generating an artificial neural network (ANN) for prediction model for onion bulbs and stem's compressive strength. $70 \%$ data was taken as training data while remaining data was divided in equal division and used for validation and testing purpose. Levenberg-Marquardt back propagation training program were taken with 500 epochs to predict the output regarding CS of stems and bulbs. According to the training, validation and testing of the data for onion stem and bulb compressive strength, prediction model follows as:

$$
\begin{aligned}
& \text { Predicted Stem CS }=0.6 \text { stem CS }+1.9 \\
& \text { Predicted Bulb CS }=0.72 \text { bulb CS }+2.1
\end{aligned}
$$

The predicted data (Fig 5) showed the linear relation between predicted value and actual output. The coefficient of determination of stem was observed to be 0.77 while it was observed as 0.76 for onion bulb. The $\mathrm{R}^{2}$ of training, validation and testing data of stem was $0.74,0.64$ and 0.81 $\%$ respectively while its value was found as $0.74,0.82$ and 0.88 for bulb which is slightly higher.

Neural network depicts that, it works on the principle of weight transfer between different nodes under different layers. Result shows that its predictability was higher as compared with regression method on the basis of coefficient
Table 3: Regression Model, standard error and $t$ value for compressive strength of onion seedlings.

\begin{tabular}{llccc}
\hline Parameter & Model & B & Std. error & $\mathrm{t}$ value \\
\hline Bulb & Constant & -5.37 & 0.74 & -7.19 \\
& Day (a) & 0.12 & 0.01 & 7.89 \\
& Diameter (b) & 2.55 & 0.23 & 10.98 \\
\multirow{3}{*}{ tem } & Constant & -2.36 & 0.61 & -3.92 \\
& Day (a) & 0.112 & 0.013 & 8.34 \\
& Diameter (b) & 0.65 & 0.26 & 2.44 \\
\hline
\end{tabular}

of determination values acquired. Hence, neural network approach is the best substitute in future for prediction in automation.

\section{CONCLUSION}

The study reveals that 60 to 70 -days old seedlings are suitable for transplanting of seedlings mechanically or by automation. The moisture content of onion seedling was 92.64-89.62\% (wb). during growing time period (30-70 days). The CF for different platform was varied from 5.24-0.58 during 30 to 70 days. Plywood and Aluminium had less influence to the outer moisture content of seedlings. However, CF was also found less for other material at the age of 60 to 70 days. The compressive strength increased with age of seedling. Analysis shows the ANN provided a better prediction model with a high coefficient of determination. Compressive strength used to design the optimized gripping force in automation/robotic transplanting system. Gathered information would be helpful for designing of effective transplanting mechanism of transplanter and proven technologies in an optimized way.

Conflicts of interest: None.

\section{REFERENCES}

Anonymous, (2021). Nursery Raising, ICAR- Directorate of Onion and Garlic Research, Pune-Nasik Highway No-50, Rajgurunagar, Pune, Maharashtra, India. [Accessed 2021 Jan 15]. https://icar.org.in/content/annual-workshop -onion-garlic-ainrpog-organized. 
ASAE, (1997). ASAE Standard, American Society of Agricultural Engineering, St. Josephs, MI USA.

Chaudhari, D., Singh, V.V. and Dubey, A.K. (2002). Refinement and adoption of mechanical vegetable transplanter for Indian condition. Agril. Engineering Today. 26 (5-6): 11-20.

Dahikar, S.S., Rode, S.V. and Deshmukh, P. (2015). An artificial neural network approach for agricultural crop yield prediction based on various parameters. International Journal of Advanced Research in Electronics and Communication Engineering. 4(1): 94-98.

Khadatkar, A., Mathur, S.M., Gaikwad, B.B., Pandirwar, A. and Shrinivas, D.J. (2020). Biometric properties of plug vegetable seedlings relevant to the design of vegetable transplanter. Journal of Agricultural Engineering. 57(1): 16-24.

Khadatkar, A., Mathur, S.M. and Dubey, K. (2020). Design, Development and Implementation of Automatic Transplanting based on Embedded System for use in Seedling Transplanters, Chinese Journal of Mechanical Engineering. DOI: 10.21203/rs.3.rs-27290/v1.

Khura, T.K., Mani, I. and Srivastava, A. P. (2010). Some engineering properties of onion crop relevant to design of onion digger. Journal of Agricultural Engineering. 47(1): 1-8.

Kumawat, L., Raheman, H. and Singh, V. (2020). Design and development of a tractor drawn automatic onion transplanter. International Journal of Current Microbiology and Applied Sciences. 9(2): 2616-2629.

Nagar, H. (2020). Application of artificial intelligence for fuel consumption prediction of a tractor in tillage operations. M.Tech. thesis, Farm Machinery and Power, Agricultural and food engineering department, Indian Institute of Technology, Kharagpur. West Bengal.

Nandede, B.M., Carpenter, G., Chillur, R., Jadhav, M.L. (2017). Development of a low cost manually operated two row vegetable transplanters. International Journal of Tropical Agriculture. 35(4): 1047-1055.

Nandede, B.M., Kumar, R. and Padhee, D. (2013). Evaluation of multistage automatic vegetable transplanter (MAVT) for pot seedlings of tomato. BIOINFOLET-A Quarterly Journal of Life Sciences. 10(1b): 193-195.

Pandirwar, A., Kumar, A., Mani, I. and Islam, S. (2015). Biometric properties of onion seedlings relevant to the development of onion seedling transplanter. Journal of Applied and Natural Science. 7(2): 768-773.

Pandirwar, A., Kumar, A., Singh, J.K., Mani, I. and Bhowmik, A. (2019). Development and evaluation of semi-automatic six row onion seedlings transplanter. Agricultural Mechanization in Asia, Africa and Latin America. 50(1): 30.

Rahul, K., Raheman, H. and Paradkar, V. (2020). Design of a 4 DOF parallel robot arm and the firmware implementation on embedded system to transplant pot seedlings. Artificial Intelligence in Agriculture. 4: 172-183.

Sakaue, O. (1996). Development of seeding production robot and automated transplanter system. Japan Agricultural Research Quarterly. 30: 221-226.

Vivek, P., Duraisamy, V.M. and Kavitha, R. (2017). Development of an automatic transplanting mechanism for protray vegetable seedlings. Madras Agricultural Journal. 104 (March (1-3): 1. 